\title{
Askim-tunets kronologi
}

\section{En tillämpad bayesiansk analys}

\section{Inledning}

Som bakgrund till sin diskussion i Viking 2015 av «boligens biografi i førromersk jernalder» publicerade Grethe Bjørkan Bukkemoen utgrävningarna i 2010 av gårdstunet vid Askim kyrka i Østfold, Norge (Bukkemoen 2010, 2015). Bosättningsområdet, som sannolikt är större än uppdragsgrävningen hade möjlighet att belägga, ligger i södra delen av ett NNVSSO-gående platt höjddrag som sannolikt varit bosättningens primära försörjningsområde (figur 1a och b).

I sin diskussion sätter Bukkemoen in platsen i det större sammanhang som präglar förändringarna av huset som social miljö och social katalysator under förromersk järnålder. I Bukkemoens välavvägda diskussion blir husen på Askim-tunet ett övertygande exempel på hur äldre och mindre hus med inga eller enstaka reparationer av den takbärande konstruktionen avlöses av större hus med behovsstyrda ombyggningar och reparationer. Bukkemoen vidareför och fördjupar diskussionen om huset som socialt rum med en form av agens (2015:95-96). De tre husen i Askim, som vi känner till i dag, framstår därför både som kontexter som förändras över tid, och som den kontextuella förändringens katalysatorer. Sedan 1990-talet kan sådana materiella dubbelkonnotationer förstås som uttryck för interaktion i sociala nätverk. Den sena vikingatidens runstenar i Mälardalen (text, ornamentik, sten och placering) är till exempel både mälardalingarnas lokala uttryck för kristendom och uttryck som skapar kristendom (Herschend 1994:101, se i förlängningen Lager 2002; Ljung 2016). Askimhusens med tiden allt noggrannare anpassning till höjdryggens NNV-SSOliga förlopp tycks indikera en allt mer medveten landskapsuppfattning där hus och landskap blir varandras komplement: Huset med sin N-S följd av funktionella rum - fjös, bostad, lager - blir landskapet, och försörjningslandskapet med sin N-S-sortering - utmark, gård, inmark - blir huset. Fjöset i norra delen av Hus 1:2 och fjösdörren i dess nordgavel (Bukkemoen 2015:figur 6) är en karakteristisk landskapsbunden modifiering av det traditionella husets arkitektur (figur 2). Förändringen betonar husdjurens koppling till betesmarken.

I denna artikel är det meningen att bygga vidare på Bukkemoens tolkning genom att formalisera diskussionen av Askim-husens C14-kronologi för att undersöka om en sådan non-intuitiv dateringsdiskussion kan stödja, precisera och fördjupa tolkningen av samspelet mellan husens och platsens biografi. Man frågar sig med andra ord om en ny typ av krono- 


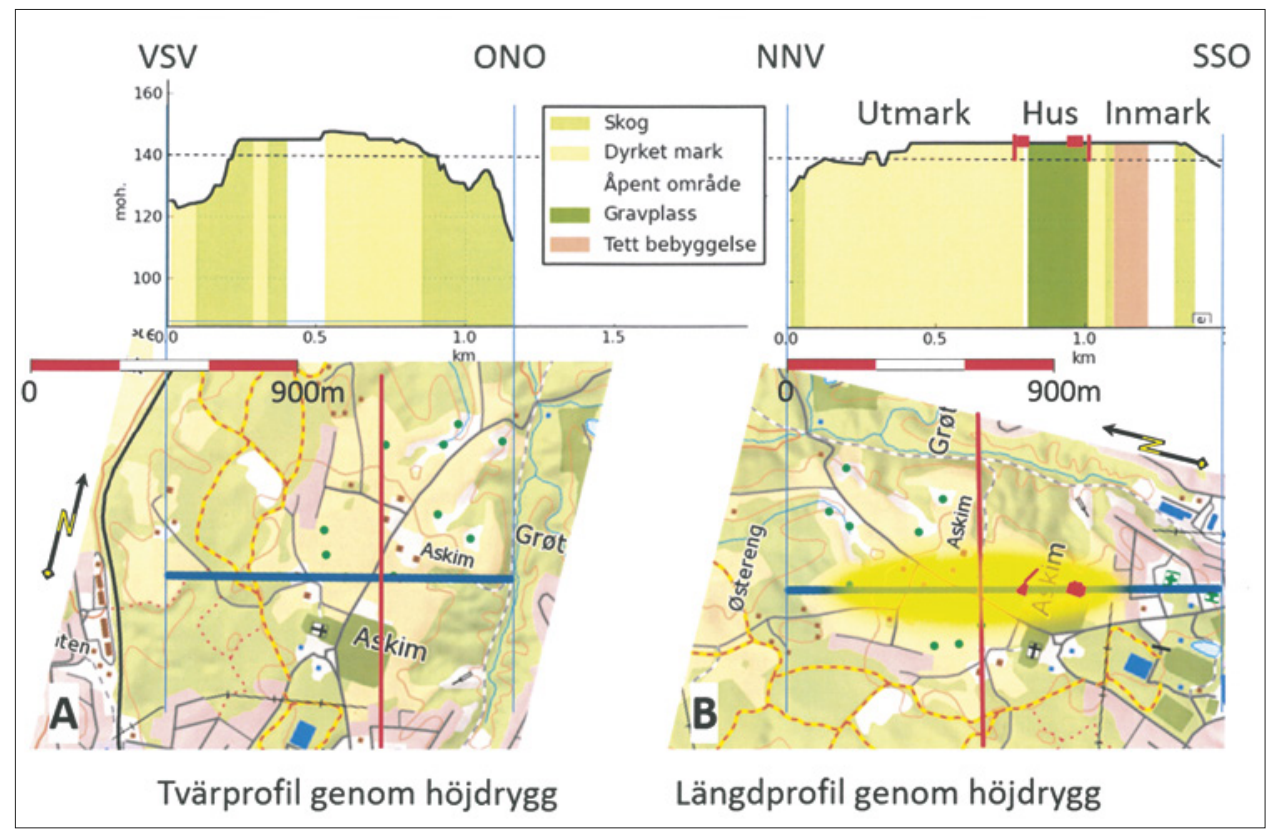

Figur 1A och B. A: Tvärsnitt som visar bosättningens placering på höjdryggen.

$B$ : Längdsnitt som antyder bosättningens förhållande till höjddragets längdriktning.

Kartgrunnlag: kartverket.no.

logisk diskussion på ett avgörande sätt ökar våra insikter? Om så är fallet, så påminner situationen i dag om situationen på 1800-talet då fyndkombinationer av karakteristiska föremål formaliserades som kronologisk metod. Även kombinationer av de element som förekom på karakteristiska föremål formaliserades till typologisk kronologi. Fyndkombinationsmetod och kronologi var inga saliggörande metoder, och det är inte bayesiansk C14-kronologi heller, men de var revolutionerande, trots sina många metodologiska och källkritiska problem. Hursomhelst är det värd att pröva om bayesiansk C14-kronologi skulle kunna revolutionera arkeologin.

\section{Kronologisk analys}

I dag behöver man som arkeolog inte längre bedöma C14-dateringarnas sannolikhetsfördelningar intuitivt, och tekniska mätproblem är numera överkomliga, se till exempel Daniel Steel (2000). Det finns flera kalibreringsprogram som tillämpar bayesiansk statistik för att lösa kalibreringar och sannolikhetsbedömningar non-intuitivt. En bayesiansk analys av arkeologiska C14-dateringar från en överplöjd bosättning bygger på en arkeologisk diskussion som till exempel argumenterar för att en serie C14-dateringar är uttryck för den tidsperiod då ett hus användes. Helt säkert kan man inte veta att så är fallet, eftersom de prov som daterats, har ett ganska fritt förhållande till bosättningskontexten, men man kan argumentera för att det är ett rimligt antagande, till exempel i Askim-fallet. Om man uppfattar dateringarna som uttryck för en period, så kan man också fråga sig när den perioden börjar och 


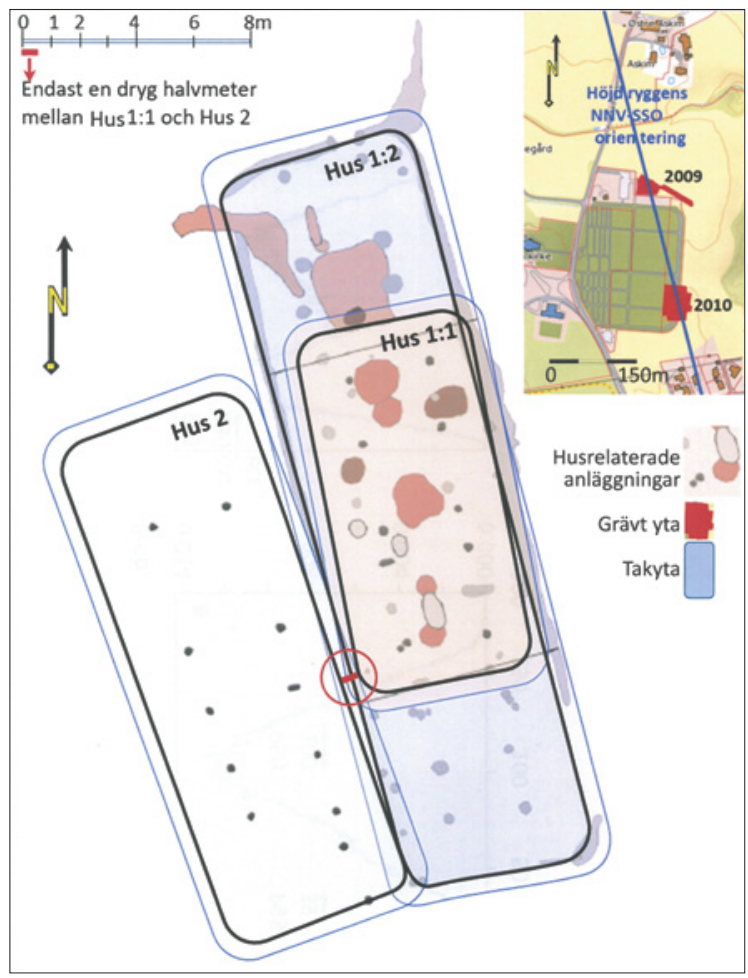

Figur 2. Det rumsliga förhållandet mellan de tre husen på Askim-tunet och deras förhållande till höjdryggens längdriktning. Även om väglinjen i platsens äldsta hus, det gråa Hus 1:1, inte överlappar väglinjen i det gröna Hus 2, så är det så trångt mellan husen att Hus 2:s vägg inte kan byggas om Hus 1:1 står kvar. Dessutom kommer de två hustaken, som sträcker sig utanför vägglinjen, $i$ konflikt med varandra. Platsens yngsta hus, det blåa hus 1:2, överlagrar de två äldre husen. Husen bildar därför en kronologisk serie: Hus 1:1, hus 2 och Hus 1.2. Husplanerna bygger på Bukkemoen 2015. Kartgrunnlag: kartverket.no.

slutar. Därför formulerar man inom bayesiansk statistik en apriorisk fråga, till exempel: Om dessa C14-prov representerar slutet på husets användningstid, under vilka år infaller då slutet? Genom att mata in fakta om de aktuella C14-dateringarna i en databas blir det möjligt för ett program att kalibrera proven och svara på frågan genom att visa hur sannolikt det är att ett visst år representerar husets första eller sista användningsår. Några år är mer sannolika än andra, och fördelningen av dessa mer eller mindre sannolika år är den bayesianska analysens aposterioriska svar på arkeologens aprioriska fråga.

När arkeologen har fått sitt svar, måste hen omedelbart fråga sig hur denna nya sannolikhetsfördelning skall bedömas. Ett rimligt sätt som tillämpas i denna artikel, är att definiera första eller sista användningsåret som ett årtal mellan två gränsvärden. Det första gränsvärdet är det år då det finns 50 \% chans att en period har börjat, eller om frågan rör slutet på perioden, 50 \% chans att den slutat. Detta år kallas P50-året, dvs. året då sannolikheten är $50 \%$. Det andra värdet är det år då det finns $95 \%$ chans att perioden har börjat eller slutat. Det är med andra ord mycket sannolikt att så är fallet. P50- och P95-året definierar med andra ord en buffert inom vilken det är rimligt att säga att en period börjat eller slutat. Gemensamt för de aposterioriska svar som arkeologen får, är att de är helt beroende av de data arkeologen matar in i databasen. Nya aprioriska frågor kan alltså behöva ställas för att få en bättre förståelse av kronologin.

Analyserna i denna artikel använder sig av programmet BCal (Buck m.fl. 1999). Metodiskt sett bottnar de arkeologiska resonemangen i Frands Herschend (2016). Som arkeolog behöver man inte betvivla BCals matematiska kvalitéer, och vill man skaffa sig initiala insikter i baye- 
siansk statistik, dvs. om Bayes' teorem, så kan man följa den pedagogiska tråden i Eliezer S. Yodkowsky (2017) eller i The Arbital Guide to Bayes's Rule (Arbital 2017). Genom att följa stegen i BCal Tutorial (BCal Tutorial 2017) lär man sig förstå och arbeta med programmet.

Arkeologer har länge (till exempel Norr 1998) och upprepade gånger senast (till exempel Peyroteo Stjerna 2016) framhållit de källkritiska problem som uppstår när man skall föra ihop naturvetenskaplig och kulturvetenskaplig kronologi - dvs. svara på frågan: Vad är det proven daterar? Sedan bayesiansk analys av C14-dateringar blivit populärt, försummar inte heller naturvetare att betona vikten av att veta vad det arkeologiskt sett är man a priori låter statistikprogrammet räkna på, och vad analysens a posteriori svar innebär (till exempel Buck och Meson 2015). Inte förvånande relativerar de källkritiska problemen i nedanstående analys ganska snart vidare kronologiska diskussioner.

Från Askim-tunet består dateringsunderlaget huvudsakligen av C14-dateringar av prov, som mer eller mindre tydligt är kopplade till vertikala och horisontella stratigrafiska iakttagel-

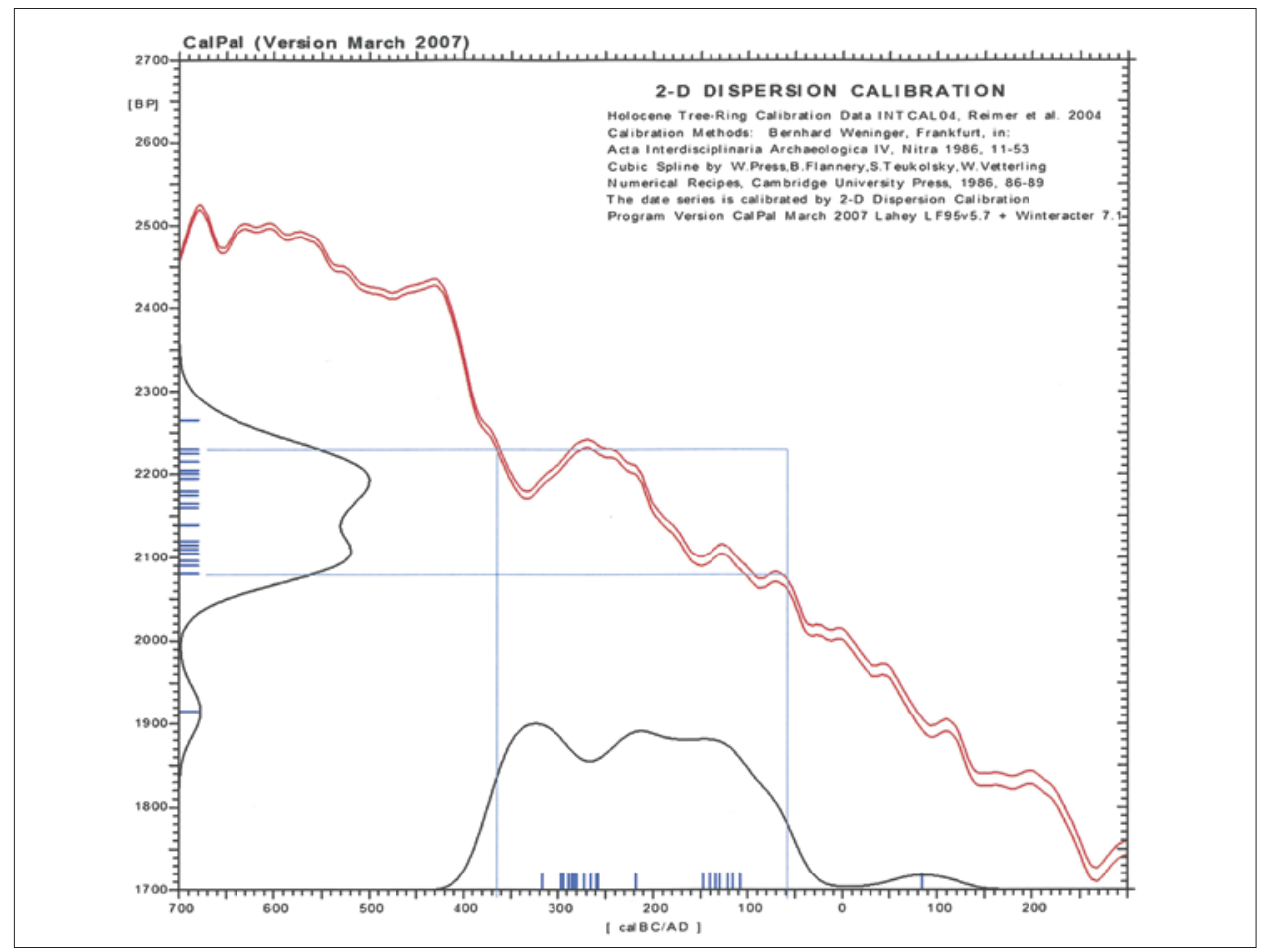

Figur 3. En generell översikt över dateringarna på Askim-tunet. Diagrammet summerar alla de 22 C14-dateringarnas sannolikheter i två kurvor. På den lodräta axeln ligger C14-årens fördelning och en markering med blåa streck av varje daterings b.p.-år. På den vågräta axeln summerar kurvan de kalibrerade kalenderåren. De blåa strecken på denna axel representerar varje provs medianår, dvs. det kalibrerade år då $50 \%$ av ett provs sannolika år är äldre eller yngre än medianåret. Den blåa fyrkanten inramar det avsnitt av kalibreringskurvan som leder till att den korta period av C14-år på den lodräta axeln blir en lång period av kalenderår på den vågräta axeln. Diagrammet bygger på dateringarna i tabell 1. 
ser. De kalibrerade resultaten tillhör en period då C14-dateringar är problematiska på grund av kalibreringskurvans flacka och allt annat än jämt fallande karaktär. Ett fall på 150 C14-år motsvaras således av drygt 300 kalenderår, snarare än av 150. Kring 2210 b.p. är fallet dock ganska brant (figur 3). Den kronologiska bilden motsägs inte av de relativt fătaliga traditionella arkeologiska föremålsfynden i de båda utgrävningsfälten (Bukkemoen 2010:9, 2015:108).

Bukkemoen (2015) hanterar dateringarna försiktigt, men materialet är komplext. Därför kan man undra om det lönar sig att föra en mer non-intuitiv diskussion av C14-dateringarnas förmåga att datera Askim-kontexten. För man en formell diskussion, så är det med det förbehåll att endast en liten del av bosättningsområdet är känt. Mycket är förstörd av Askim kyrkogård.

Från de två grävningarna på Askim-tunet (Bukkemoen 2010, 2015) finns det i allt 22 C14-dateringar: Tre är från kyrkogårdens norra kant (fält 2009) och 19 från tunet i sydost (fält 2010). I princip kan man anse att dessa prov daterar en bebyggelseperiod som tillhör förromersk järnålder. Äldre prov är mer spridda än yngre (tabell 1, rad 1-12, mot 13-21). Dessutom är ett prov betydligt yngre än alla andra (tabell 1, rad 22). Det daterade materialet är dels frön och sädeskorn, dels björk, i ett fall tillsammans med hassel, från stolphål, väggränna, härdar och kokgropar. Frönas egenålder är försumbar, men veden har en okänd egenålder även om den kanske inte alltid är hög. Att det förhåller sig så, antyder till exempel den äldsta dateringen som just är en bit björk från en av eldstäderna i Hus 1:1, platsens äldsta hus (tabell 1, rad 1 och figur 2).

Tabell 1. De 22 C14-dateringarna från Askim fält 2009 och 2010. Se Bukkemoen (2010, 2015).

\begin{tabular}{|l|l|l|l|l|l|l|l|l|}
\hline Rad & Lab. Nr. & b.p. år & $\mathbf{\sigma}$ & Fält & Anl & Kontext & Material & Egenålder \\
\hline 1 & TRa-1466 & 2265 & 30 & 2010 & eldstad & Hus 1:1 & Björk & Ved** $^{*}$ \\
\hline 2 & TRa-2038 & 2230 & 30 & 2010 & takb-sth & Hus 1 & Korn & 1-år \\
\hline 3 & TRa-2039 & 2225 & 30 & 2010 & takb-sth & Hus 1 & Korn & 1-år \\
\hline 4 & Tra 517 & 2215 & 30 & 2009 & kokgr & Öppen & Björk & småved \\
\hline 5 & TRa-1467 & 2205 & 30 & 2010 & eldstad & Hus 1:1 & Björk & småved \\
\hline 6 & TRa-2037 & 2205 & 30 & 2010 & takb-sth & Hus 1 & Korn & 1-år \\
\hline 7 & TRa-1471 & 2200 & 30 & 2010 & väggrän & Hus 1:2* & Björk & småved \\
\hline 8 & Tra516 & 2195 & 30 & 2009 & kokgr & Öppen & Björk & småved \\
\hline 9 & TRa-2043 & 2180 & 30 & 2010 & takb-sth & Hus 2 & Korn & 1-år \\
\hline 10 & TRa-2044 & 2175 & 35 & 2010 & takb-sth & Hus 2 & Gräsfrö & 1-år \\
\hline 11 & Tra 518 & 2165 & 30 & 2009 & kokgr & Öppen & Björk & småved \\
\hline 12 & TRa-1468 & 2160 & 25 & 2010 & eldstad & Hus 1:1 & Björk & småved \\
\hline 13 & TRa-1473 & 2140 & 30 & 2010 & kokgr & Hus 1 & Bkörk & småved \\
\hline 14 & TRa-2035 & 2120 & 35 & 2010 & sth & Hus 1 & korn & 1-år \\
\hline 15 & TRa-2042 & 2115 & 35 & 2010 & takb-sth & Hus 1 & Korn/gräs & 1-år \\
\hline 16 & TRa-1470 & 2110 & 30 & 2010 & eldstad & Hus 1:2 & Björk & småved \\
\hline 17 & TRa-1465 & 2105 & 30 & 2010 & kokgr & Hus 1 & Björk & småved \\
\hline 18 & TRa-2036 & 2096 & 30 & 2010 & takb-sth & Hus 1 & korn & 1-år \\
\hline 19 & TRa-1469 & 2090 & 25 & 2010 & eldstad & Hus 1:2 & Björk & småved \\
\hline 20 & TRa-2041 & 2090 & 30 & 2010 & takb-sth & Hus 1 & frö & 1-år \\
\hline 21 & TRa-1474 & 2080 & 30 & 2010 & kokgr & Hus 1 & Björk & småved \\
\hline 22 & TRa-1472 & 1915 & 35 & 2010 & kokgr & Öppen & Björk & småved \\
\hline
\end{tabular}

Anm: * Kontaminering. ${ }^{* *}$ Hög egenålder. 
Prob.

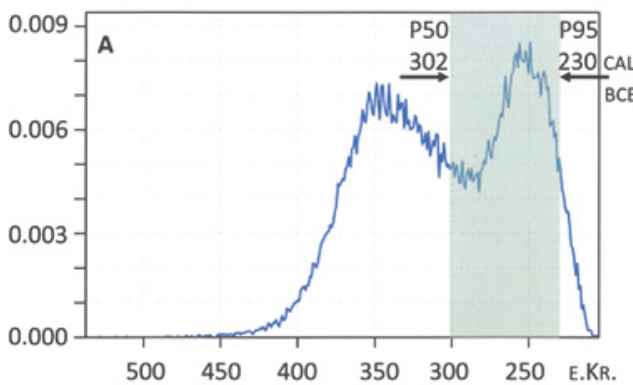

Prob.

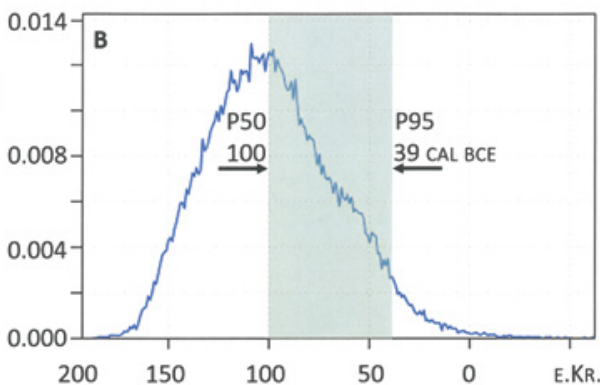

Figur 4A och B. Diagrammen illustrerar A: början på bebyggelseperioden på Askim-tunet och B: slutet. Diagrammen bygger på dateringarna i tabell 1.

Hus 1:1 ligger under Hus 1:2. De äldsta C14-dateringarna knyter sig till Hus 1:1, medan de två dateringarna från Hus 2 strax väster om Hus 1:1 är yngre. Rent byggnadstekniskt kan inte Hus 2 stå samtidigt med Hus 1:1 eller Hus 1:2. Husen, som kan antas ha ett mittskepp som utgör ca. 50 \% av husbredden, står så nära varandra att det skapar (obegripliga) konflikter mellan väggförlopp och takskägg. Det betyder att Hus 2 är yngre än Hus 1:1, men äldre än Hus 1:2. Som Bukkemoen visar innebär stratigrafin att Hus 1:1 i sin tur är äldre än Hus 1:2. Detta kronologiska skelett tillåter oss att först närma oss en generell datering av bebyggelseperioden, utan att glömma de komplikationer som björkens egenålder och olika former av kontaminering skulle kunna skapa. Vi kan därför i stora drag söka belysa bosättningens början och slut mot bakgrund av alla 22 dateringar.

Genom att fråga sig när det är sannolikare att bosättningsperioden har börjat eller slutat än att den inte gjort det (dvs. fråga efter P50-året), och genom att fråga när den med $95 \%$ sannolikhet har börjat och har slutat (dvs. fråga efter P95-året), får vi en uppfattning om periodens början och slut, figur $4 \mathrm{a}$ och $\mathrm{b}$. Man kan med andra ord säga att bosättningen börjar i 3. århundradet f.Kr. och att den slutar med att Hus 1:2 brinner under 1. århundradet f.Kr. Vid mitten av 200-talet f.Kr. är det sannolikt att bebyggelsen finns, och vid mitten av 00 -talet f.Kr. är det sannolikt att den inte finns. Bebyggelseperioden ser med andra ord ut att vara ca. 200 år lång och ligga i senare delen av förromersk järnålder.

Att en bebyggelse under 200 år rymmer en serie om tre hus, är inte onaturligt med tanke på det sista husets livsförlopp (Bukkemoen 2015). Ändå skulle man vilja kunna bedöma om den intuitiva känslan man har av en kontinuerlig bebyggelse, stärks av en mer formell dateringsanalys.

Genom att kritiskt granska tabell 1 kan man skapa en husdateringstabell, tabell 2. I den möter man den kronologiska ordning man förväntar sig mot bakgrund av de kontextuella bindningar som Bukkemoen diskuterar: Hus 1:1, Hus 2 och Hus 1:2. Men det finns också en tydlig kontaminering: äldre kol i det sista husets, Hus 1:2's, väggränna (TRa-1471 2200 \pm 30 b.p.). Vi kan gripa oss an materialet på två sätt. Det första är en analys av de 7 kontextuellt precisa dateringarna (tabell 2). Urvalet är så litet att det kanske inte skildrar husens användningstid korrekt. En datering från Hus 1:1 (TRa-1468 2160 25 b.p.) ser till exempel ut att

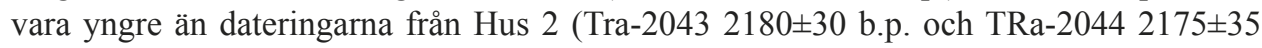


Tabell 2. Husdaterande C14-dateringar med varierande egenålder och starkare eller svagare kontextuell bindning. Luckan mellan TRa-1468 och TRa-1473, som Bukkemoen (2015) noterar, bildar tidsmässig gräns mellan Hus 1:1 och Hus 1:2. Man kan inte veta om TRa-1468 kontaminerar sin kontext.

\begin{tabular}{|c|c|c|c|c|c|c|c|}
\hline Lab. Nr. & b.p. år & $\sigma$ & Anl & Kontext & Material & Egenålder & Kontextualisering \\
\hline TRa-1466 & 2265 & 30 & eldstad & Hus $1: 1$ & Björk & Ved* & Säker Hus 1:1 \\
\hline TRa-2038 & 2230 & 30 & takb-sth & Hus 1 & Korn & 1-år & Sannolik Hus 1:1 \\
\hline TRa-2039 & 2225 & 30 & takb-sth & Hus 1 & Korn & 1-år & Sannolik Hus 1:1 \\
\hline TRa-1467 & 2205 & 30 & eldstad & Hus 1:1 & Björk & småved & Säker Hus 1:1 \\
\hline TRa-2037 & 2205 & 30 & takb-sth & Hus 1 & Korn & 1-år & Sannolik Hus 1:1 \\
\hline TRa-1471 & 2200 & 30 & väggrän & Hus $1: 2^{* *}$ & Björk & småved & Sannolik Hus 1:1 \\
\hline TRa-2043 & 2180 & 30 & takb-sth & Hus 2 & Korn & 1-år & Säker Hus 2 \\
\hline TRa-2044 & 2175 & 35 & takb-sth & Hus 2 & Gräsfrö & 1-år & Säker Hus 2 \\
\hline TRa-1468 & 2160 & 25 & eldstad & Hus 1:1† & Björk & småved & Säker Hus 1:1 \\
\hline TRa-1473 & 2140 & 30 & kokgr & Hus 1 & Bkörk & småved & Sannolik Hus 1:2 \\
\hline TRa-2035 & 2120 & 35 & sth & Hus 1 & korn & 1-år & Sannolik Hus 1:2 \\
\hline TRa-2042 & 2115 & 35 & takb-sth & Hus 1 & Korn/gräs & 1-år & Sannolik Hus 1:2 \\
\hline TRa-1470 & 2110 & 30 & eldstad & Hus $1: 2$ & Björk & småved & Säker Hus 1:2 \\
\hline TRa-1465 & 2105 & 30 & kokgr & Hus 1 & Björk & småved & Sannolik Hus 1:2 \\
\hline TRa-2036 & 2096 & 30 & takb-sth & Hus 1 & korn & 1-år & Sannolik Hus 1:2 \\
\hline TRa-1469 & 2090 & 25 & eldstad & Hus $1: 2$ & Björk & småved & Säker Hus 1:2 \\
\hline TRa-2041 & 2090 & 30 & takb-sth & Hus 1 & frö & 1-år & Sannolik Hus 1:2 \\
\hline TRa-1474 & 2080 & 30 & kokgr & Hus 1 & Björk & småved & Sannolik Hus 1:2 \\
\hline TRa-1472 & 1915 & 35 & kokgr & Öppen & Björk & småved & Sannolik Hus 1:2 \\
\hline
\end{tabular}

Anm: * Hög egenålder. ** Kontaminering: gammalt kol i väggränna. † Kontaminering?

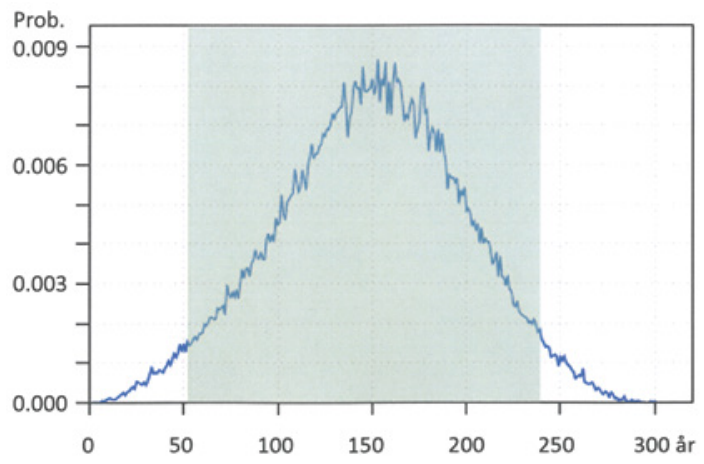

Figur 5. I tabell 2, den högra spalten, kan tre dateringar stratigrafiskt säkert knytas till Hus 1:1 och två till Hus 1:2. Ytterligare två dateringar kan knytas till Hus 2, om vilket man vet att det är yngre än Hus 1:1 och äldre än Hus 1:2. Mot bakgrund av denna aprioriska tolkning kan man i BCal fråga hur stort avståndet $i$ tid är mellan den tidpunkt som representerar slutet på hus 1:1 och den som representerar början på Hus 1:2. BCal:s aposterioriska svar är den sannolikhetsfördelning som tecknas av den blåa grafen. Man ser på grafen att de mest sannolika tidsavstånden ligger kring 150 år. Samtidigt ser man att tidsavståndet med 95\% sannolikhet är större än 52 år och mindre än 241 år. 


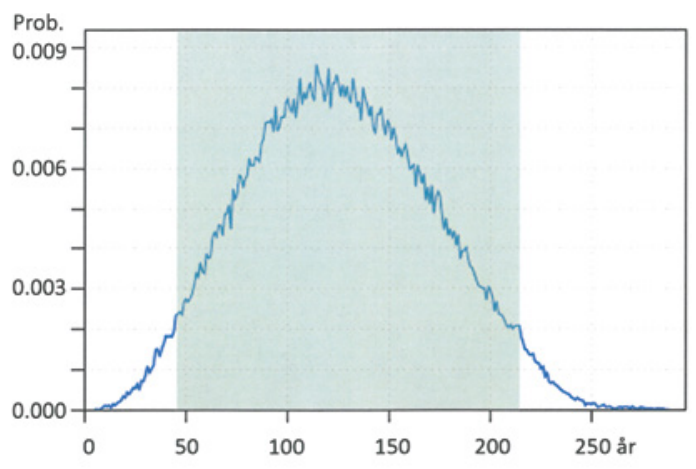

Figur 6. I tabell 2, högra spalten, har 7 C14-prov tolkats tillhöra Hus 1:1 medan 9 prov tillhör Hus 1:2. Två dateringar daterar Hus 2, om vilket man vet att det är yngre än Hus 1:1 och äldre än Hus 1:2. Mot bakgrund av denna förnyade aprioriska tolkning (jfr. figur 5) kan man $i$ BCal fråga hur stort avståndet $i$ tid är mellan den tidpunkt som representerar slutet på Hus 1:1 och den som representerar början på Hus 1:2. BCal:s aposterioriska svar är den sannolikhetsfördelning som tecknas av den blåa grafen. Man ser på grafen att de mest sannolika tidsavstånden ligger kring 120 år. Samtidigt ser man att tidsavståndet med $95 \%$ sannolikhet är större än 44 år och mindre än 214 år. Det viktiga är hursomhelst att tidsavståndet med stor sannolikhet är större än en husgeneration (se Herschend 2009:142156). Hus 2 kan med andra ord ha stått ensamt på platsen, och det är inte osannolikt att platsen under en del av perioden mellan Hus 1:1 och Hus 1:2 inte varit bebyggt.

b.p.). Analyserar man tidsavståndet mellan Hus 1:1 och 2, samt mellan Hus 2 och Hus 1:2, så finns det inget, men mellan Hus 1:1 och Hus 1:2 är avståndet åtminstone 52 år-sannolikt större (figur 5).

Om denna analys är tillförlitlig är svårt att säga, pga. få dateringar, egenåldersproblem och kalibreringskurvans förlopp. Det verkar å andra sidan osannolikt att Hus 2, som helt saknar ombyggnader, skulle ha stått i mer än 52 år. Bukkemoen (2015:106) finner inte att Hus 2 varit huvudhuset på en gård, bland annat på grund av att ingen härd påträffades, men om vi avstår från att utesluta huset för att inte samtidigt utesluta platskontinuitet, så bör vi pröva att än en gång datera eventuella tidsskillnader mellan dem. Ett andra sätt att göra detta är att föra ihop dateringarna som det sker i kolonnen «kontextualisering» längst till höger i tabell 2, och än en gång datera tidsskillnaden mellan husen. Mellan Hus 1:1 och Hus 2, samt mellan Hus 2 och Hus 1:2, finns sannolikt inga tidsavstånd, men mellan Hus 1:1 och Hus

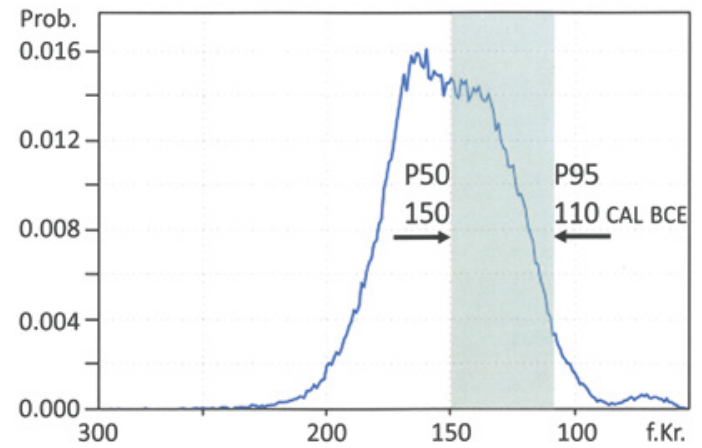

Figur 7. Diagram som illustrerar den tidsbuffert mellan P50- och P95- året då Hus 1:2 sannolikt uppfördes. Dateringen bygger på de 9 Hus 1:2-dateringar som pekas ut i tabell 2, högra spalten, samt på det faktum att Hus 1:2 är yngre än Hus 1:1 och Hus 2. 
1:2 är avståndet åtminstone 44 år och sannolikt större (figur 6). Det verkar med andra ord fortfarande osannolikt att det tillsynes oreparerade Hus 2 skulle ha stått i mer är 44 år och snarare kring 100 år. Därför är det osannolikt att det finns bebyggelsekontinuitet mellan de tre husen.

Eftersom skillnaden mellan de få analyserna i figur 5 och de många i figur 6 i praktiken är liten, dvs. eftersom det sannolikt finns en hiatus mellan husen, så kan det vara värd att fråga sig när Hus 1:2 börjar användas. P50- respektive P95-året är 150 och 110 f. Kr (figur 7). Därför började man sannolikt bygga Hus 1:2 någon gång mellan år 150 och $110 \mathrm{f} . \mathrm{Kr}$. Ovan framgick det att huset sannolikt brinner någon gång mellan 100 och 39 f.Kr. (figur 4b).

\section{Diskussion - den kronologiska analysen}

I min analys av C14-dateringarna från Askim har de kronologiska resultaten inte avgörande rubbat Bukkemoens (2015) mer intuitiva analys. Tvärtom har den stöttat hennes modell genom att definiera Hus 1:2 som ett hus som stått ca. 70 år, dvs. under flera husgenerationer (och ägare) i slutet av förromersk järnålder. Analysen har dessutom visat på en tidsmässig lucka mellan Hus 1:1 och Hus 1:2, som Bukkemoen inte finner belägg för (2015:101). Analysen öppnar med andra ord för en diskussion som ser de tre husen som skilda husperioder. Hus 1:1 är platsens första, och det byggdes någon gång i början av tredje århundradet f.Kr. (figur 4a). Hus 1:2 är dess sista, och det brann någon gång i första hälften av första århundradet före Kristus och sannolikt innan 40 f.Kr.

Den non-intuitiva kronologiska analysen sätter årtal och kronologiska ramar kring Askim-bosättningen och dess kontexter. Det motverkar i praktiken, för det första, den försiktighet som den intuitiva dateringen måste bekänna sig till eftersom den inte på ett tydligt sätt kan visa vad resultatet blir om man omformulerar grunden för en datering. I fallet Askim visade det sig till exempel att dateringar som utgår från de säkra kontexterna i tabell 2 inte avgörande skiljer sig från de resultat som utgår från alla kontextuella tolkningar i tabell 2. På grund av sin försiktighet tenderar den intuitiva dateringen, för det andra, att i praktiken skapa kontinuerliga bosättningsförlopp för att den inte metodiskt kan bedöma eventuella bebyggelseavbrott eller fluktuationer i bebyggelsens intensitet. Fluktuation och avbrott är hursomhelst något den non-intuitiva analysen kan hantera, och det är en stor tillgång eftersom kontinuitet är en mycket signifikant kulturhistorisk tolkning. När det visar sig att den kan sättas i fråga, visar det sig också att den non-intuitiva dateringsdiskussionen till exempel kan stödja, precisera och fördjupa tolkningen av samspelet mellan husens och platsen biografi.

\section{Diskussion - huset som monument}

I sin analys av Hus 1 och dess två faser såg Bukkemoen (2015:106) att man, sedan man slutat bo i Hus 1:1 och börjat bygga Hus 1:2, förseglade Hus 1:1 med ett lerlager som bevarats över husets härdar. Bukkemoen ser lerlagret som golvet i det nya huset (Hus 1:2). I praktiken kan man tacka detta lager för att Hus 1:1 kunnat bevaras så väl även sedan man byggt Hus 1:2 ovanpå dess rester. Eftersom den bayesianska analysen resulterar i ett tidsgap mellan Hus 1:1 och Hus 1:2, och eftersom lerlagret inte utgör golvlagret $\mathrm{i}$ hela eller en viss del av Hus 1:2, så kan man också tänka sig att lagret ursprungligen täckt Hus 1:1 och att Hus 
1:1 under en tid, kanske ca. 100 år, legat som ett husmonument, en brandtomt skyddat genom ett lager och/eller veneration. Husmonument från förromersk järnålder är inte helt okända i Sydskandinavien. Man kan peka på husen från Gørding Hede (Andersen 1951) eller Løvel syd (Beck och Kaldal Mikkelsen 2006) och på det indirekta bevis som kommer till uttryck i att gamla hus i Grøntoft respekteras av senare hus. Här bygger man inte hus på gamla husrester förrän byggelsen närmar sig sitt sista skede (se Herschend 2009:154-156). Oberoende av om det är tal om ett skyddande lager eller ett golvlager mellan husen 1:1 och 1:2, kan man därför se Hus 1:1 som ett ursprungligt platshävdande hus som sedan det övergivits blivit ett monument över huset som byggnad och socialt rum. Sett i detta perspektiv är det dåligt bevarade Hus 2 ett senare hus från en tid då man inte längre funnit det nödvändigt att förse platsen med fler husmonument. Att Hus 2 är dåligt bevarat, beror i den variant av modellen som diskuteras här på att ingen funnit det nödvändigt att bevara eller skydda det för att hävda en plats som redan hävdats med Hus 1:1 och det (ursprungliga) liv som försiggick där.

I det som de arkeologiska utgrävningarna än så länge pekar ut som en sista fas vid Askim kyrka, väljer man att bygga en ny typ av hus, en månggenerationsgård ovanpå det hus som en gång inaugurerade en första plats i en lämplig miljö. Med Hus 1:2 kommer platsen och miljön i stället att tillhöra huset. Under ett par hundra år sker det med andra ord en samhällelig förändring som betyder att platsen från att hävdas genom närvaro under en husgeneration, tas i besittning genom en månggenerationsgård.

När Hus 1:2 brinner, sker det sannolikt för att det skall ske genom en ritual. Bukkemoen (2015:109-110) finner tecken på att huset tömts, så när som på keramik runt härden, för att brännas ned på ett sätt som visar att huset inte bara avslutar ett månggenerationsboende. Ritualen avslutar i stället den interagerande dyaden hushåll-jordbruk. Hus 1:1 skapade platsen, Hus 2 vidareförde den, och Hus 1:2 avslutade den genom att göra huset till gravbål. Än en gång är parallellen till huset på Gørding Hede påtaglig. Också detta hus tömdes, så när som på keramiken runt eldstaden, innan det brändes ned (Andersen 1951). I det samtida, men tätbebyggda Nørre Tranders är de offerhandlingar som avslutar ett hus, brännoffer, under det att de som markerar dess början är deponeringsoffer (Hansen 2006). Flera indicier tyder med andra ord på att man under förromersk järnålder ställer huset och härden i ordning för att bisätta huset, härden och dess keramik med hjälp av ett bål, som vore huset en individ.

Om människors agens, som de flesta arkeologer tar för givet, kan komma till uttryck i deras gravar, och om gravmonumenten i någon mån påverkar framtida generationers världsbild, så bör man också vara öppen för att husets agens även som monument kan vara av betydelse för de generationer som senare bebor platsen. På samma sätt som man monumentaliserar sina förfäder, så kan man monumentalisera deras hus i den mån de inte helt enkelt står kvar, underhålls och byggs om.

Även långt senare, till exempel från 300-talet och framåt, när man väljer att riva ned och försegla den lilla hallen i Uppåkra, den som också uppfattas som ett renodlat kulthus (Larsson och Söderberg 2013:238-248), kan man argumentera för att den stratigrafiska serien av nedrivna och förseglade hus, som varje ny byggnad står på, är monument över hallens agens - inte nödvändigtvis kulthusbegreppets denotationer utan de enskilda husens bidrag till generationernas historia. Kanske är det typiskt att man i Uppåkra valde att låta dryckeskärlen - metallbägaren och glasskålen - ligga kvar i det förseglade golvet som en 
pendang till den äldre järnålderns keramik runt härden. Från och med yngre romersk järnålder måste man med andra ord vara öppen för att överklassen knyter an till traditionella uppfattningar om människan och huset. Att tankar om kopplingen mellan människa, grav och hus förs vidare, kan man finna belägg för i Marianne Hem Eriksens diskussion av hus och grav i järnålder och vikingatid (Eriksen 2016).

Ännu mycket senare, till exempel i Emmanuel Le Roy Laduries (1975) studie av byn Montaillou under 1300-talet, kommer tanken att huset har agens till ett pregnant uttryck, och betydelsen av husets så väl som gravens agens blir uppenbar, även om Le Roy Ladurie inte använder sig av just detta begrepp. Dock framhåller han följande i samband med inkvisitionens bestraffning av kättaren personligen så väl som hans hus och grav:

\footnotetext{
Les inquisiteurs, pour frapper doublement, détruisaient la demeure villageoise du coupable; et, s'il était décédé, sa sépulture; ceci afin de le priver, par la même occasion, de repos dans l'au-delà. - För att slå dubbelt, demolerade inkvisitorerna den skyldiges hus i byn och, om han var död, hans grav; detta för att vid ett och samma tillfälle förhindra honom att hinsides vila i frid. (Le Roy Ladurie 1975:624, översatt av författaren).
}

För att vara säkra på att kättaren inte skall komma i åtnjutande av Himmelens eviga hushåll förstör man huset $\mathrm{i}$ byn och graven eftersom man kan förvänta sig att dessa materiella kontexters agens kommer att verka för sin kätterska hushållsmedlem på samma sätt som Gud verkar för medlemmarna i sitt. Människor och hus interagerar med varandra som sociala varelser genom närvaro. I Montaillou är huset ett nav at återvända till (Le Roy Ladurie 1975:624).

I det långa skandinaviska tidsperspektivet tycks «rätt genom närvaro» bli kvar i utmarksmiljöer (till exempel Sumtangen, Blehr 2012 eller Hälsingland, Lindholm m.fl. 2013:30), medan «rätt genom besittning» och så småningom äganderätt (Bukkemoen 2015:97) i kraft av att gårdens tun och hus blir den täta bebyggelsens kännemärke (till exempel de utmätta tomterna i Præstestien, Herschend 2009:260-271; Siemen 2000 eller i St. Darum, Søvsø 2010, eller Gilltuna med dess manifesta tun, Sundkvist och Eklund 2014).

\section{Avslutande kommentar}

De senaste 20 årens exploateringsarkeologi har synliggjort en av järnåldersarkeologins stora kvalitéer i Sydnorge: möjligheten att inom en begränsade bosättningsnisch gräva ut ett föränderligt samhälles långa utvecklingsförlopp. Med grävningar för E6 och E18 kring Oslofjorden, till exempel Bustgård, Missingen, Rødbøl och Ringdal (Bårdseth 2009; Gjerpe och Rødsrud 2008:143; Gjerpe och Østmo 2008:39; Vikshåland m.fl. 2007) har de mindre nischerna aktualiserats och med dem nya kronologiska mönster. Exploateringsgrävningar är sällan vetenskapligt ideala även om just resultaten från många små grävningar kan läggas ihop till mer generella resultat, som det visas till exempel av Bukkemoen (2015). Därför borde man skapa forskningsprojekt som mer fullständigt gräver ut bosättningsnischer som redan berörts av exploateringsarkeologiska undersökningar.

Att döma av Askim-fallet kan non-intuitiv kronologisk analys baserad på bayesiansk statistik skapa kronologiska förutsättningar för en fördjupad förståelse av kulturhistoriska bosättningsförlopp som komplexa fenomen. Det beror dels på att metoden är non-intuitiv, dels på att man som arkeolog tvingas klargöra sina aprioriska frågor. Samtidigt är det påtagligt att moderna källkritisk medvetna uppdragsarkeologiska utgrävningar och C14-date- 
ringarnas minskande standardavvikelser skapar nya förutsättningar som spelar den bayesianska analysen i händerna. Därför bör man förfina samspelet mellan boplatsundersökningarnas uppdragsarkeologiska fältmetodik och non-intuitiv kronologisk analys.

\section{Summary}

\section{The chronology of the Askimtun. An applied Bayesian analysis}

In order to show its potential, this article introduces a non-intuitive chronological Bayesian analysis of the pre Roman Iron Age settlement site at Askim Church in Østfold, Norway. The archaeological background is provided by an article by Grethe Bjørkan Bukkemoen (2015). The calibration program used to perform the Bayesian analyses is BCal (Buck m.fl. 1999). The analysis suggests that the settlement commences in the early part of the 3rd c. $\mathrm{BCE}$ and comes to an end in the early part of the 1st BCE. Presently, its continuation during the Roman Iron Age is unknown. The main part of the analysis concerns the dating of the houses 1:1 and 1:2 which overlap each other - House 1:1 being the older of the two. The time gap between the two buildings seems too large to be filled by the adjacent House 2, which is younger than House 1:1 and older than House 1:2. In the discussion the chronological analysis is used to corroborate and develop Bukkemoen's discussion on the pre Roman Iron Age farm house as a social agent. It is suggested that the pre Roman Iron Age house, which initially is determined by the subsistence landscape, is replaced by the late pre Roman Iron Age house, which in its turn defines the subsistence landscape.

\section{Litteratur}

Andersen, Harald

1951 Et landsbyhus på Gørding Hede. Kuml 1951:40-64.

Arbital

2017 Bayes s Rule: Guide. Elektroniskt dokument, https://arbital.com/p/bayes_rule/?1=1zq, besökt 25. april 2017.

$\mathrm{BCal}$

2017 BCal. An on-line Bayesian radiocarbon calibration tool. Elektroniskt dokument, http://bcal.sheffield.ac.uk, besökt 9. februari 2017.

BCal Tutorial

2017 BCal: The Tutorial. Elektroniskt dokument, http://bcal.shef.ac.uk/tutorial/tutorial.html, besökt 25. april 2017.

Beck, Malene R. och Dorthe Kaldal Mikkelsen

2006 Løvel syd: bebyggelsespor fra yngre bronzealder og ældre germansk jernalder. Bygherrerapport

Blehr, Otto nr. 13. Viborg Stiftsmuseum. Viborg.

2012 Medieval reindeer drives at Sumtangen, Hardangervidda. Two interpretations. Fornvännen 107(2):115-122.

Buck Caitlin E., J. Andrés Christen och Gary N. James

1999 BCal: an on-line Bayesian radiocarbon calibration tool. Internet Archaeology, 1999(7), http://dx.doi.org/10.11141/ia.7.1.

Buck, Caitlin E. och Bo Meson

2015 On being a good Bayesian. World Archaeology 47(4):567-584, http://dx.doi.org/10.1080/00438243.2015.1053977. 
Bukkemoen, Grethe Bjørkan

2010 Bunnlag av gravhaug, kokegroper og dyrkningslag. Askim prestegård 99/1, Askim, Østfold. Rapport arkeologisk utgravning. Kulturhistorisk museum, Oslo.

2015 Ett hus - mange livsløp. Boligens biografi i førromersk jernalder belyst gjennom et gårdsanlegg i Askim. Viking 78:94-118.

Bårdseth, Gro Anita

2009 The Roman Age Hall and the Warrior Aristocracy. Reflections upon the Hall at Missingen, South-East Norway. Norwegian Archaeological Review 42(2):146-158.

Calpal

2017 Eine archäologische revolution. Elektroniskt dokument,

http://monrepos-rgzm.de/forschung/ausstattung.html\#calpal, besökt 25. april 2017.

Gjerpe, Lars Erik och Christian Rødsrud

2008 Rødbøl 19, 20 og 21 - hus og boplasspor fra romertid, jernvinne fra middelalder og graver fra eldre jernalder. I Hus, boplass og dyrkningsspor. E18-prosjektet Vestfold bind 3, redigerat av Lars Erik Gjerpe, s. 143-193. Varia 73. Kulturhistorisk museum, Oslo.

Gjerpe, Lars Erik och Mari Østmo

2008 Ringdal 13 - Hus fra romertid-merovingertid og graver fra førromersk jernalder. I Hus, boplass og dyrkningsspor. E18-prosjektet Vestfold bind 3, redigerat av Lars Erik Gjerpe, s. 39-141. Varia 73. Kulturhistorisk museum, Oslo.

Hansen, Jesper

2006 Offertradition og religion i ældre jernalder i Sydskandinavien med særlig henblik på bebyggelseofringer. Kuml 55:117-167.

Eriksen, Marianne Hem

2016 Commemorating Dwelling. The Death and Burial of Houses in Iron and Viking Age Scandinavia. European Journal of Archaeology 19(3):477-496.

Herschend, Frands

1994 The recasting of a symbolic value - Three case studies on rune-stones. Occasional Papers in Archaeology 3. Uppsala Universitet, Uppsala.

2009 The Early Iron Age in South Scandinavia. Social Order in Settlement and Landscape. Occasional Papers in Archaeology 46. Uppsala Universitet, Uppsala.

2016 Towards a standardized discussion of priors in Bayesian analyses of ${ }^{14} \mathrm{C}$ dated archaeological periods. A study based on the dates from Gjøsund. Journal of Archaeology and Ancient History 19:1-28.

Lager, Linn

2002 Den synliga tron. Runstenskors som en spegling av kristnandet $i$ Sverige. Occasional Papers in Archaeology 31. Uppsala Universitet, Uppsala.

Larsson, Lars och Bengt Söderberg

2013 Brända hallar - diskontinuitet och kontinuitet. Ett järnåldersresidens i Uppåkra, Sydsverige. Fornvännen 108(4):238-248.

Le Roy Ladurie, Emmanuel

1975 Montaillou, village occitan de 1294 à 1324. Gallimard, Paris.

Lindholm Karl-Johan, Emil Sandström och Ann-Kristin Ekman

2013 The Archaeology of the Commons. Journal of Archaeology and Ancient History 10:3-49.

Ljung, Cecilia

2016 Under runristad häll. Tidigkristna gravmonument i 1000-talets Sverige. Stockholm Studies in Archaeology 67 (1-2). Explicare, Stockholm.

Norr, Svante

1998 Radiocarbon-dating and the chronology of the Gene settlement. I Suionum hinc civitate. Nya undersökningar kring norra Mälardalens äldre järnålder, redigerat av Kent Andersson, s. 263-274. Occasional Papers in Archaeology 19. Uppsala University, Uppsala. 
Peyroteo Stjerna, Rita

2016 On Death in the Mesolithic. Or the Mortuary Practices of the Last Hunter-Gatherers of the South-Western Iberian Peninsula, 7th-6th Millennium BCE. Occasional Papers in Archaeology

Siemen, Palle 60. Uppsala Universitet, Uppsala.

2000 Prcestestien. Bind 1 och 2 Arkæologiske rapporter nr 3. Esbjerg Museum, Esbjerg.

Steel, Daniel

2001 Bayesian Statistics in Radiocarbon Calibration. Philosophy of Science 68(3):153-164.

Sundkvist, Anneli och Susanne Eklund

2014 Gilltuna - där man följde traditionen. Den första storskaligt undersökta tunagården. SAU rapport 2014(4). Societas Archaeologica Upsaliensis, Uppsala.

Søvsø, Morten

2010 Et udsnit af en landsby fra omkring år 500 e.Kr. udgravet i St. Darum ved Ribe. By, marsk og geest 22:5-20.

Vikshåland Leif Håvard, Barbara Maria Sageidet och Paula Utigard Sandvik

2007 Bustgård. Neolittisk kulturlag, helleristninger fra bronsealder og hus fra eldre jernalder (lokalitet 33). I Hus og gard langs E6 i Fredrikstad og Sarpsborg kommunar. E6-prosjektet Østfold, Bind 3, redigerat av Gro Anita Bårdseth, s. 101-142. Varia 67. Kulturhistorisk museum, Oslo.

Yodkowsky, Eliezer S.

2017 Bayes' Theorem for the curious and bewildered; an excruciatingly gentle introduction.

Elektroniskt dokument, http://www.yudkowsky.net/rational/bayes, besökt 25. april 2017. 